\title{
Confirmatory Analysis of Ethylglucuronide in Urine by Liquid-Chromatography/Electrospray Ionization/Tandem Mass Spectrometry According to Forensic Guidelines
}

\author{
Wolfgang Weinmann, Patrick Schaefer, and Annette Thierauf \\ Institute of Legal Medicine, Forensic Toxicology, University Hospital, Freiburg, Germany
}

\author{
André Schreiber \\ Applied Biosystems, Darmstadt, Germany \\ Friedrich Martin Wurst \\ Psychiatric University Clinic, Basel, Switzerland
}

\begin{abstract}
$\beta$-D-ethylglucuronide (EtG) is a stable Phase II metabolite of ethanol which can be detected in urine samples several days after elimination of ethanol. It is a useful diagnostic parameter for monitoring abstinence of alcoholics in alcohol withdrawal treatment. For this purpose, determination in urine is mainly performed by LC-MS, LC-MS/MS, or by GC-MS. For the mass spectrometric identification and detection of controlled substances in more sensitive fields such as forensic toxicology, workplace drug testing, doping analysis, and veterinary organic residue control, official guidelines have been released requiring a chromatographic separation and a minimum of two mass spectrometric transitions of the analyte. However, for detection of EtG none of the published LC-MS/MS methods could fulfill the minimum requirements of any of these guidelines. Therefore, an existing LC-MS/MS method has been modified by monitoring further MS/MS transitions instead of only one (deprotonated molecule $[\mathrm{M}-\mathrm{H}]^{-} /$product ions: $\mathrm{m} / \mathrm{z} 75,85,113$, and 159 optional) with the aim of withstanding administrative or court scrutiny in forensic or workplace drug testing cases. Full method validation has been performed in accordance to guidelines of the German Society of Toxicology and Forensic Chemistry (GTFCh) and requirements of ISO 17025. One application field in the United States is a workplace monitoring program to detect surreptitious alcohol use among recovering health professionals, who by contract had agreed on total abstinence after drug and alcohol withdrawal therapy. (J Am Soc Mass Spectrom 2004, 15, 188-193) (c) 2004 American Society for Mass Spectrometry
\end{abstract}

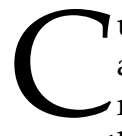
urrent biological markers for monitoring recent alcohol consumption remain suboptimal with regard to sensitivity and specificity. Furthermore, these biomarkers can be influenced by age, gender, and a variety of substances and non-alcohol-associated diseases, and do not fully cover the time axis for alcohol intake. Conjugation of ethanol with activated glucuronic acid in the presence of membrane-bound mitochondrial UDP glucuronyl transferase represents a minor detoxification pathway for ethanol: About 0.02$0.06 \%$ (mean) of the dose of ethanol administered is

Published online December 17, 2003

Address reprint requests to Dr W. Weinmann, Forensic Toxicology, University Hospital, Institute of Legal Medicine, Albertstrasse 9, D-79104 Freiburg, Germany. E-mail: weinmann@sun11.ukl.uni-freiburg.de recovered as $\beta$-D-ethylglucuronide $(\mathrm{EtG})$ in urine in humans [1] and-dose dependent- $0.5-1.5 \%$ in rabbits [2]. EtG is a non-volatile, water-soluble, stable, direct metabolite of ethanol that can be detected in various body fluids, tissues and hair. EtG $\left(\mathrm{C}_{8} \mathrm{H}_{14} \mathrm{O}_{7}\right)$ has a molecular weight of $222 \mathrm{~g} / \mathrm{mol}$, and the melting point (decomposition temperature) is about $150^{\circ} \mathrm{C}$. Shortly after the initial consumption of even small amounts of ethanol, EtG is formed. It has been detected in urine up to $80 \mathrm{~h}$ after the complete elimination of alcohol from the body and was not detectable in teetotalers with a 0.1 $\mathrm{mg} / \mathrm{L}$ cut-off $[3,4]$. EtG is unique in covering this important time span of one to three days after alcohol uptake. In urine, it can be detected longer than ethanol. Therefore, EtG meets the need for a sensitive and specific marker to elucidate alcohol use not detected by 
Table 1. Methods which have been successfully used for the detection of EtG

\begin{tabular}{|c|c|c|c|c|}
\hline Method & $\begin{array}{l}\text { Derivatization } \\
\text { Specimen } \\
\text { Internal standard } \\
\end{array}$ & $\begin{array}{l}\text { Ionization } \\
m / z \text {-values or transitions } \\
\text { for detection }\end{array}$ & Chromatographic details & Ref. \\
\hline GC-MS & $\begin{array}{l}\text { Silylation (MSTFA) } \\
\text { Serum/urine } \\
D_{5}-E^{-} G^{b}\end{array}$ & $\begin{array}{l}\text { EI } \\
m / z \text { 160, 261, 405 } \\
\text { (ISTD: } 164,266,410^{a} \text { ) }\end{array}$ & (5\%-phenyl)-methylpolysiloxane (DB 5) & {$[13,31]$} \\
\hline GC-MS & $\begin{array}{l}\text { Silylation (MSTFA) } \\
\text { Hair } \\
\text { Methylglucuronide }\end{array}$ & $\begin{array}{l}\text { EI } \\
m / z 261,292,375,405^{a} \\
\left.\text { (ISTD: } 391^{a}\right)\end{array}$ & (5\%-phenyl)-methylpolysiloxane (DB 5) & {$[16]$} \\
\hline GC-MS & $\begin{array}{l}\text { Perfluorpropionylation } \\
\text { Serum } \\
\text { Propylglucuronide }\end{array}$ & $\begin{array}{l}\text { EI } \\
m / z 405^{a}, 365,289,259 \\
\left.\text { (ISTD: } 405^{a}, 365,289,259\right)\end{array}$ & 100\% dimethylpolysiloxane (DB 1) & [32] \\
\hline LC-MS (SIM) & $\begin{array}{l}\text { No derivatization } \\
\text { Serum } \\
\text { No internal standard }\end{array}$ & $\begin{array}{l}\text { ESI neg. } \\
m / z 221^{a}\end{array}$ & $\begin{array}{l}\text { (a) Column: TSK-Gel Amide-80, } 250 \mathrm{~mm} \times \\
\text { 4.6mm, (acrylamide-type); Tosoh, Tokyo, } \\
\text { Japan) } \\
\text { Eluent: } 30 \mathrm{mM} \text { ammonium acetate-acetonirile } \\
\text { (30:760, v/v) } \\
\text { (b) Column: Thermoquest Hypercarb } \\
\text { (100mm } \times 2 \mathrm{~mm}) \text {, Keystone/Thermo Sci. }{ }^{c} \\
\text { Eluent: } 25 \mathrm{mmol} \text { formic acid/acetronitrile } \\
(95: 5 \mathrm{v} / \mathrm{v})\end{array}$ & {$[11]$} \\
\hline LC-MS MS & $\begin{array}{l}\text { No derivatization } \\
\text { Serum, urine, hair } \\
D_{5}-E t G\end{array}$ & $\begin{array}{l}\text { ESI neg. } \\
221-75^{\mathrm{a}} \\
\text { (ISTD: } 226-75)\end{array}$ & $\begin{array}{l}\text { (a) Column: RP } \mathrm{C} 18^{\mathrm{b}} \text {; } \\
\text { Eluent: } 0.1 \% \text { formic acid (isocratic) } \\
\text { (b) Column: Synergy polar RP; polar- } \\
\text { endcapped phenyl-propyl (Phenomenex) } \\
{[3,14] \text {, Eluent: } 0.1 \% \text { formic acid (isocratic) with }} \\
\text { post-column addition of acetonitrile }\end{array}$ & {$[12]$} \\
\hline
\end{tabular}

standard testing [5-13]. Furthermore, EtG has been detected in hair samples [14-16] and post-mortem tissues (liver, brain, fat tissue [17]) of alcohol addicts. Recently, the determination of ethylglucuronide in urine was shown to be superior to ethanol as a proof of recent alcohol consumption in a workplace drug testing program of recovering health professionals [18].

For the detection of EtG in urine and serum, immunoassays are under current development [19-21]. However, to date the development of an immunoassay with sufficient sensitivity and specificity has been unsuccessful. Therefore, mass spectrometric methods, such as GC-EI-MS after derivatization, and LC-MS or LCMS/MS with negative electrospray ionization, using selected ion monitoring (of the deprotonated molecule, $\mathrm{m} / \mathrm{z} 221$ ) and one MS/MS-transition (deprotonated molecule to fragment ion; $m / z$ 221-75), respectively, have been applied to the analysis of urine (Table 1). Quantitative analysis has been performed by use of penta deuterium-labeled internal standard $\left(D_{5}-E t G\right)$ or the glucuronides of ethanol homologues (methylglucuronide, propylglucuronide). Since EtG is a very polar substance, precipitation or dilution prior to analysis by GC-MS and LC-MS have been used for sample clean-up in most published papers. LC-MS or LC-MS/MS methods are advantageous in comparison with GC-MS methods because of the reduced need for derivatization and shorter analysis times (10 min per chromatographic run) $[4,12]$. In our experience, GC-MS with derivatization requires much more system maintenance than does LC-MS, because of the high load of polar matrix which is present in urine samples. This is important for the analysis of large numbers of samples.

Guidelines for urine drug testing in the clinical laboratory have been approved by the National Committee for Clinical Laboratory Standards (NCCLS) [22]. When the results of urine drug testing can affect an individual's reputation, job status, or freedom, forensically-acceptable analytical procedures must be utilized, and the findings must be legally defensible. For a confirmatory analysis in forensic toxicology, guidelines require chromatographic separation and at least three ions for compound detection or identification with SIM when a single quadrupole GC-MS is used [23]. For the identification of residues by LC-MS/MS analysis, European guidelines require chromatographic separation and a minimum of two transitions for substance detection; when LC-MS (single MS) is used, three characteristic ions are required [24, 25]. None of the published LC-MS or LC-MS/MS methods for EtG listed in Table 1 fulfilled these requirements, since either only one ion with optimized "in-source" CID conditions was used with a single-quadrupole instrument $[4,11]$, or only one 
characteristic transition was used for EtG by LC-MS/ MS-analysis [12, 14].

Our aim was to develop and to validate an LCMS/MS method with at least two transitions for EtG which would fulfill the requirements for forensic confirmatory analysis, thus being suitable for workplace drug testing programs and forensic toxicological analysis.

\section{Experimental}

EtG and $D_{5}-E t G$ standards were obtained from Medichem (Stuttgart, Germany). HPLC-grade acetonitrile and formic acid (analytical grade) were purchased from Merck (Darmstadt, Germany). Deionized water was prepared with a cartridge-deionizer from Memtech (Moorenweis, Germany). Sample preparation: To 0.1

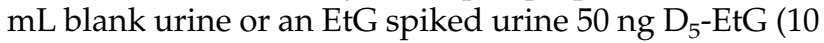
$\mu \mathrm{L}$ of an aqueous solution, $5 \mu \mathrm{g} / \mathrm{mL}$ ) was added and the sample diluted with $0.25 \mathrm{~mL}$ methanol. The sample was centrifuged $(14,000 \mathrm{rpms})$ for ten min at $4^{\circ} \mathrm{C}$. Next, $0.25 \mathrm{~mL}$ of the clear supernatant were transferred to a glass autosampler vial $(1.5 \mathrm{~mL})$ and evaporated to dryness by use of a vacuum concentrator $\left(60 \mathrm{~min}, 45^{\circ} \mathrm{C}\right.$, 1 mbar, Alpha RVC, Martin Christ, Osterode, Germany). The dried residue was then redissolved with $0.14 \mathrm{~mL}$ of $0.1 \%$ formic acid, transferred to a glass micro insert ( $0.2 \mathrm{~mL}$ volume), and $10 \mu \mathrm{L}$ were injected into the LC-MS/MS system.

The LC-MS/MS system consisted of an API 365 triple-quadrupole mass-spectrometer fitted with a turbo ionspray interface (Applied Biosystems/Sciex, Darmstadt, Germany) and a Shimadzu HPLC system (two pumps LC10AD Shimadzu, Duisburg, Germany). Analyses were performed with electrospray ionization using a turbo ionspray source in negative mode. EtG was separated at $40^{\circ} \mathrm{C}$ on a polar-endcapped phenylpropyl reversed phase column (Synergy Polar-RP $250 \times$ $2 \mathrm{~mm}, 4 \mu \mathrm{m})$ with a guard column $(4 \mathrm{~mm} \times 2 \mathrm{~mm}$, same packing material) (Phenomenex, Aschaffenburg, Germany). The mobile phase consisted of aqueous $0.1 \%$ formic acid (vol/vol) at a flow-rate of $0.2 \mathrm{~mL} / \mathrm{min}$. To enhance signal intensity, acetonitrile was added with a post-column "tee" before the effluent enters the turbo ionspray interface. With a six-port/two-way switching valve (Labpro, Rheodyne, Rohnert Park, CA) the LCeffluent was admitted to the MS interface only between 4 and 6 mins of the chromatographic retention time. The turbo ionspray source was operated at $400^{\circ} \mathrm{C}$ with an ionization voltage of $-4 \mathrm{kV}$, and nitrogen as curtain gas and nebulizer gas. Optimization of the ion source and MS/MS parameters for data acquisition were done by infusion of a $1 \mu \mathrm{g} / \mathrm{mL}$ solution of EtG $(20 \mu \mathrm{l} / \mathrm{min})$ with a syringe-pump coupled with a tee-union to the outlet of the HPLC system using the autotune function of the Analyst software (Applied Biosystems/Sciex, Darmstadt, Germany). Analysis was performed by multireaction monitoring, using the precursor ion at $m / z 221$ and the fragment ions at $m / z 75,85,113$, and 159 for EtG,
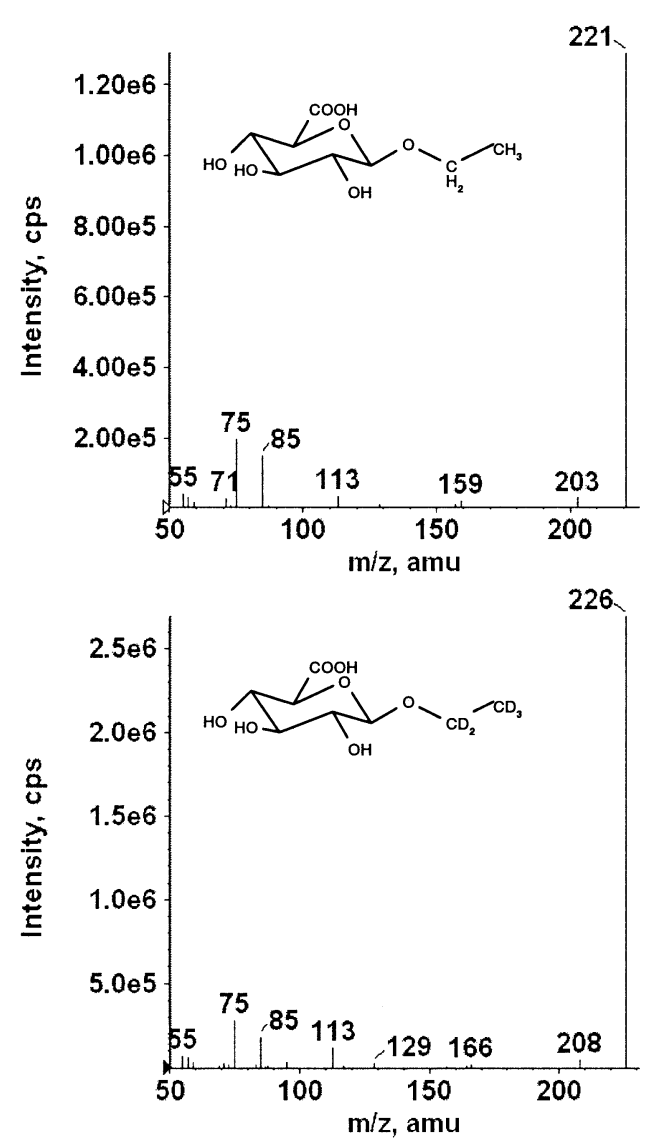

Figure 1. Product-ion spectra of EtG and $D_{5}-E t G$ (precursor ions $m / z 221$ and 226).

and precursor ion at $m / z 226$ and fragment ion at $m / z 75$ for the internal standard $D_{5}-E t G$ (dwell-times: $200 \mathrm{msec}$ for each transition, defragmentation potential: $-16 \mathrm{~V}$, focusing potential: $-140 \mathrm{~V}$, entrance potential: $3 \mathrm{~V}$, collision energy: $-16 \mathrm{eV}$, collision cell exit potential: $-10 \mathrm{~V}$, collision gas pressure: $2.4-0.7 \times 10^{-5}$ torr nitrogen; unit resolution for Q1 and Q3). For method validation VALISTAT program was used [26].

\section{Results}

The most abundant product ions of EtG and $\mathrm{D}_{5}$-EtG $(\mathrm{m} / \mathrm{z} 75,85$, and 113$)$ (see Figure 1$)$ result from the

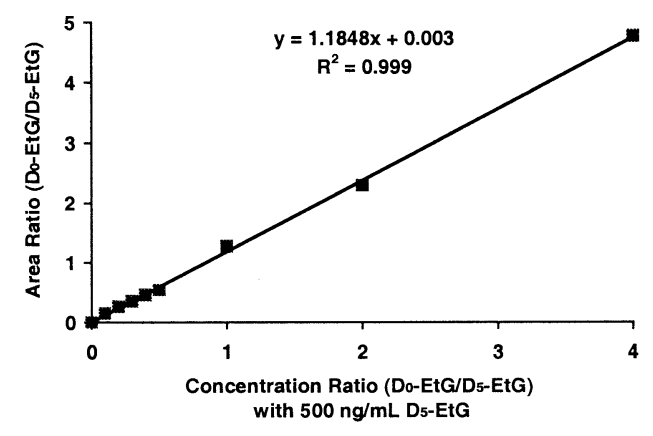

Figure 2. Calibration with spiked urine samples. 

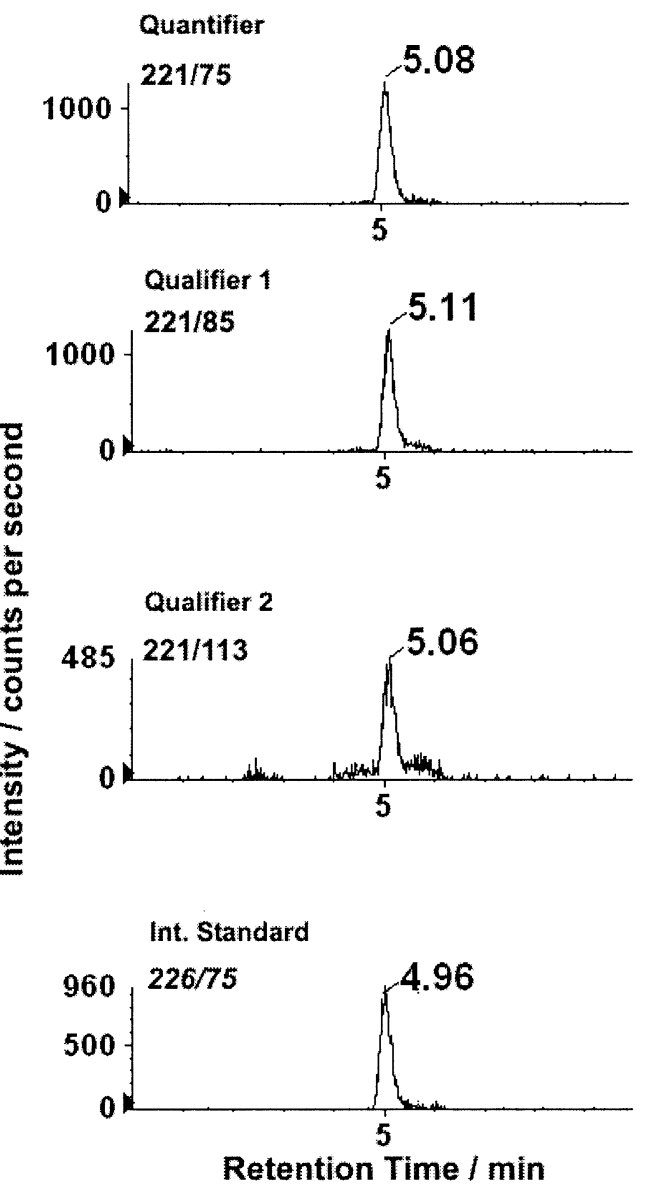

Figure 3. Ion chromatograms of urine sample of a female volunteer $8 \mathrm{~h}$ after drinking sparkling wine with $9 \mathrm{~g}$ ethanol content (495 $\mathrm{ng} / \mathrm{mL}$ EtG was determined).

glucuronic acid not including the aglycon ethanol. The ions with low abundance result from lactonization or loss of water $(\mathrm{m} / \mathrm{z} 203)$, additional decarboxylation $(\mathrm{m} / \mathrm{z}$ $159)$, loss of ethanol ( $\mathrm{m} / \mathrm{z} 113)$, and water (95) or CO (85). In positive ionization mode, $\beta$-D-glucuronides, e.g., of morphine, codeine and nor- $\Delta^{9}$-carboxy-tetrahydrocan-

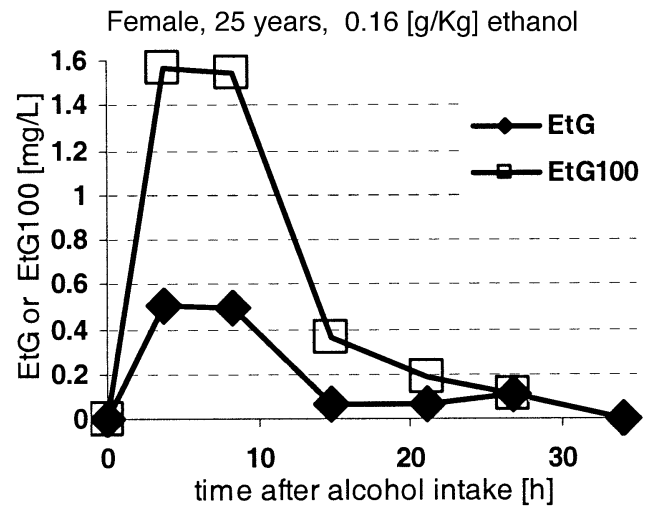

Figure 4. Time course of urine EtG and EtG100 (normalized to creatinine concentration of $100 \mathrm{mg} / \mathrm{dL}$ ) of a female volunteer after drinking sparkling wine $(0.1 \mathrm{~L})$ with a total of $9 \mathrm{~g}$ ethanol. nabinol (cannabis metabolite), show a totally different fragmentation pattern (neutral loss of the glucuronide at $\mathrm{C}_{1}$, mass difference $176 \mathrm{u}$ and further fragmentation of the aglycon) $[27,28]$. However, in negative mode the ions at $m / z 75,85$, and 113 could also be generated either by CID or by in-source CID of other glucuronides of xenobiotics or endogenous substances and could give rise to mass spectrometric interferences if not separated by liquid chromatography and by precursor ion filtering using MS/MS.

Validation has been performed using a common validation procedure [29] with a Microsoft Excel based validation program (VALISTAT [26]). A linear calibration model was used for transition 221/75 (base peak) as quantifier and transition 221/85 (96\% base peak intensity) as qualifier. The less abundant transitions $221 / 113$ ( $46 \%$ base peak intensity) and 221/159 (15\% base peak intensity) were not used for method validation, but can be used as additional qualifiers for analyte identification. The calibration curve was linear over the range from 50 to $2000 \mathrm{ng} / \mathrm{mL}$ (see Figure 2). Linear regression [23] with equidistant calibration levels $(0,50$, $100,150,200$, and $250 \mathrm{ng} / \mathrm{mL}$ ) was used for the calculation of LOD and LOQ with a significance level of 33\% $(\mathrm{k}=3$ ): LOD: $52 \mathrm{ng} / \mathrm{mL}$ (with $\alpha$-error $10 \%$ for the qualifier) LOQ: $152 \mathrm{ng} / \mathrm{mL}$ ( $\alpha$-error $1 \%$ for quantifier). Intra-assay repeatability and accuracy (bias) were tested by replicate analysis of two quality control samples (200 $\mathrm{ng} / \mathrm{mL}$ and $2000 \mathrm{ng} / \mathrm{mL}$, respectively) in eight assays, and produced results as follows. Intra-assay repeatabilty: for $200 \mathrm{ng} / \mathrm{mL}, 4.19 \%$ relative standard deviation (RSD) and $0.03 \%$ bias; for $2000 \mathrm{ng} / \mathrm{mL}, 3.78 \% \mathrm{RSD}$ and $1.94 \%$ bias.

Figure 3 shows the typical ion chromatograms of the quantifier and two additional qualifiers for EtG in a urine sample ( $495 \mathrm{ng} / \mathrm{mL} \mathrm{EtG)} \mathrm{obtained} \mathrm{from} \mathrm{a} \mathrm{female}$ volunteer $8 \mathrm{~h}$ after drinking $0.1 \mathrm{~L}$ of sparkling wine $(9 \mathrm{~g}$ ethanol) in a controlled study. Figure 4 shows the time course of EtG elimination in this study; due to the correlation of EtG concentration and creatinine concentration [30], EtG100 was calculated by normalizing the measured EtG- and creatinine concentrations to a creatinine concentration of $100 \mathrm{mg} / \mathrm{dL}$. In this study with nine volunteers, no EtG was detected in the baseline urine samples collected after one week of abstinence, and no interferences with other compounds were found in the retention time window of $\mathrm{EtG}(5.1 \pm 0.3 \mathrm{~min})$ for the transitions of the quantifier and qualifiers.

\section{Conclusions}

A validated LC-MS/MS method has been developed which fulfills the requirements for forensic confirmatory analysis for EtG in urine through the use of at least two MS/MS-transitions for compound identification, instead of only one transition as published recently by others. Although this could easily be achieved, none of the previous LC-MS(MS) methods ever took this possibility into consideration, mainly because the discussion 
of validity of results produced by LC-MS/MS methods by selected reaction monitoring has just started in the workplace and forensic drug testing environments.

Method validation has been performed according to guidelines of the GTFCh, ISO 17025, and general rules for bioanalytical method validation [29], which are rather detailed for testing specificity, regression models, intra-assay repeatability, and accuracy. In analyzing more than 1000 urine samples from clinical and forensic cases, we have found that LC-MS/MS has advantages over GC-MS analysis [16, 31, 32] because of higher sample throughput by shorter analysis time (10 min per run instead of approximately $20 \mathrm{~min}$ ), no need for derivatization as in GC-MS, and less contamination of the chromatographic system.

Until now, no EtG has been detected in baseline urine samples of volunteers of our study or those studied by others. These volunteers were social drinkers; baseline urine was analyzed after total abstinence for several days. However even low amounts of ethanol in the range of 1 to $2 \mathrm{~g}$, which could be ingested with "alcohol-free" beverages, pharmaceutical preparations containing ethanol, or by food containing low amounts of ethanol (e.g., cakes, fruit juices) could give rise to low urine EtG concentrations. To overcome the potential of "false positive" results due to the high sensitivity of the LC-MS/MS method, further studies must include the definition of cut-off values for EtG determination for diagnostic purposes. Furthermore, inter-individual differences of glucuronidation rates have to be investigated, and the proposal of a cut-off should include normalization to the creatinine concentration.

\section{Acknowledgment}

This work was supported by the Wissenschaftliche Gesellschaft der Universität Freiburg.

\section{References}

1. Dahl, H.; Stephanson, N.; Beck, O.; Helander, A. Comparison of Urinary Excretion Characteristics of Ethanol and Ethylglucuronide. J. Anal. Toxicol. 2002, 26, 201-204.

2. Kamil, I. A.; Smith, J. N.; Williams, R. T. A New Aspect of Ethanol Metabolism: Isolation of Ethylglucuronide. Biochem. J. 1952, 51, 32-33.

3. Janda, I.; Alt, A. Improvement of Ethylglucuronide Determination in Human Urine and Serum by Solid-Phase Extraction. J. Chromatogr. B Biomed. Sci. Appl. 2001, 758, 229-234.

4. Stephanson, N.; Dahl, H.; Helander, A.; Beck, O. Direct Quantification of Ethylglucuronide in Clinical Urine Samples by Liquid Chromatography-Mass Spectrometry. Therap. Drug Monitor. 2002, 24, 645-651.

5. Wurst, F. M.; Kempter, C.; Seidl, S.; Alt, A. Ethylglucuronide-A Marker of Alcohol Consumption and a Relapse Marker with Clinical and Forensic Implications. Alcohol Alcohol. 1999, 34, 71-77.

6. Wurst, F. M.; Schüttler, R.; Kempter, C.; Seidl, S.; Gilg, T.; Jachau, K.; Alt, A. Can Ethylglucuronide be Determined in Postmortem Body Fluids and Tissues? Alcohol Alcohol. 1999, $34,260-261$.
7. Wurst, F. M.; Kempter, C.; Metzger, J.; Seidl, S.; Alt, A. Ethylglucuronide-A Marker of Recent Alcohol Consumption with Clinical and Forensic Implications. Alcohol 2000, 20, 111-116.

8. Wurst, F. M.; Metzger, J. W. On Behalf of the WHO/ISBRA Study on Biological State and Trait Markers of Alcohol Use and Dependence. The Direct Ethanol Metabolite Ethylglucuronide is a Specific Marker of Recent Alcohol Consumption. Alcohol Clin. Exp. Res. 2002, 26, 1114-1119.

9. Wurst, F. M.; Vogel, R.; Jachau, K.; Varga, A.; Alling, C.; Alt, A.; Skipper, G. E. Ethylglucuronide Discloses Recent Covert Alcohol Use Not Detected by Standard Testing in Forensic Psychiatric Inpatients. Alcohol Clin. Exp. Res. 2003, 27, 471-476.

10. Schmitt, G.; Droenner, P.; Skopp, G.; Aderjan, R. Ethylglucuronide: An Unusual Ethanol Metabolite in Humans. Synthesis, Analytical Data, and Determinaton in Serum and Urine. J. Anal. Toxicol. 1995, 19, 91-94.

11. Nishikawa, M.; Tsuchihashi, H.; Miki, A.; Katagi, M.; Schmitt, G.; Zimmer, H.; Keller, T.; Aderjan, R. Determination of Ethylglucuronide, a Minor Metabolite of Ethanol, in Human Serum by Liquid Chromatography-Electrospray Ionization Mass Spectrometry. J. Chromatogr. B Biomed. Sci. Appl. 1999, 726, 5-110.

12. Wurst, F. M.; Kempter, C.; Seidl, S.; Alt, A. Ethylglucuronide-A Marker of Alcohol Consumption and a Relapse marker with Clinical and Forensic Implications. Alcohol Alcohol. 1999, 34, 71-77.

13. Alt, A.; Wurst, F. M.; Seidl, S. Bestimmung von Ethylglucuronid in Urinproben mit dem internen Standard $\mathrm{D}_{5}$-Ethylglucuronid. Blutalkohol 1997, 34, 360-365.

14. Janda, I.; Weinmann, W.; Kuehnle, T.; Lahode, M.; Alt, A. Determination of Ethylglucuronide in Human Hair by SPE and LC-MS/MS. Forens. Sci. Int. 2002, 128, 59-65.

15. Alt, A.; Janda, I.; Seidl, S.; Wurst, F. M. Determination of Ethylglucuronide in Human Hair. Alcohol Alcohol. 2000, 35, 313-314.

16. Skopp, G.; Schmitt, G.; Pötsch, L.; Drönner, P.; Aderjan, R.; Mattern, R. Ethylglucuronide in Human Hair. Alcohol Alcohol. 2000, 35, 283-285.

17. Janda, I. Bestimmung des Alkoholkonsummarkers Ethylglucuronid in Körperflüssigkeiten, Haaren und GewebenMethodenentwicklung und Validierung. Dissertation, University of Ulm, Germany, 2001; pp 85-88.

18. Skipper, G.E.; Schaefer, P.; Thierauf, A.; Weinmann, W.; Dierkes, J.; Wurst, F.M. Detection of Surreptitious Alcohol Use Among Health Professionals Recovering from Substance-Related Disorders Using a New Marker, Ethyl Glucuronide, unpublished.

19. Schmitt, G.; Aderjan, R.; Kirchner, M.; Zimmer, H. Enzymimmunoassay und GC-MS zur Bestimmung von Ethylglucuronid in Serum und Urin. Blutalkohol 1998, 25, 428-433.

20. Zimmer, H.; Schmitt, G.; Aderjan, R. Preliminary Immunochemical Test for the Determination of Ethylglucuronide in Serum and Urine: Comparison of Screening Method Results with Gas Chromatography-Mass Spectrometry. J. Anal. Toxicol. 2002, 26, 11-16.

21. Wurst, F. M.; Metzger, J.; Jauchau, K.; Seidl, S.; Pridzun, L.; Janda, I.; Alt, A. The Direct Ethanol Metabolite Ethylglucuronide: A Specific Marker of Recent Alcohol Consumption. In New and Upcoming Markers of Alcohol Consumption; Wurst, F. M., Ed.; Steinkopff-Springer Verlag: Darmstadt, 2001; pp 62-74.

22. Shoemaker, M. J.; Earley, R. J.; Gorsky, J. E.; Jenny, R. W.; Leiendecker-Foster, C.; Markus, W. R.; Moore, N.; Welch, M. J. Urine Drug Testing in the Clinical Laboratory; Approved Guideline, 1999. (http://www.nccls.org/free/TDM8-A.pdf accessed May 20, 2003). 
23. Aderjan, R.; Babel, B.; Briellmann, T.; Daldrup, T.; Demme, U.; Hallbach, J.; Hartung, M.; Harzer, K.; Herbold, M.; von Meyer, L.; Moeller, M.; Musshoff, F.; Schmitt, G.; Weinmann, W. Anlage zu den Richtlinien der GTFCh zur Qualitätssicherung bei forensisch-toxikologischen Untersuchungen. Anhang A: Anforderung an einzelne Analysenmethoden. Toxichem + Krimtech2000, 67, 13-16. (http://www.gtfch.org/ GTFChneuEngl.htm accessed May 20, 2003).

24. Stolker, A. A. M.; Stephany, R. W.; van Ginkel, L. A. Identification of Residues by LC-MS. The Application of New EU Guidelines. Analusis 2000, 28, 947-951.

25. Rivier, L. Criteria for the Identification of Compounds by Liquid Chromatography-Mass Spectrometry and Liquid Chromatography-Multiple Mass Spectrometry in Forensic Toxicology and Doping Analysis. Anal. Chimica Acta 2002, 492, 69-82.

26. Schmidt, G.; Herbold, M.; Peters, F. Qualitaetssicherung im forensich-toxikologichen Labor and VALISTAT 1.0. (http:// www.pts-gtfch.de/topd.htm).

27. Weinmann, W.; Svoboda, M. Fast Screening for Drugs of
Abuse by Solid-Phase Extraction Combined with Flow-Injection Ionspray Tandem Mass Spectrometry. J. Anal. Toxicol. 1998, 22, 319-328.

28. Weinmann, W.; Vogt, S.; Goerke, R.; Mueller, C.; Bromberger, A. Simultaneous Determination of THC-COOH and THCCOOH-Glucuronide in Urine Samples by LC-MS/MS. Forens. Sci. Int. 2000, 113, 381-387.

29. Peters, F. T.; Maurer, H. H. Bioanalytical Method Validation and Its Implications for Forensic and Clinical Toxicology-A Review. Accred. Qual. Assur. 2002, 7, 441-449.

30. Dahl, H.; Stephanson, N.; Beck, O.; Helander, A. Comparison of Urinary Excretion Characteristics of Ethanol and Ethyl Glucuronide. J. Anal. Toxicol. 2002, 26, 201-204.

31. Seidl, S.; Wurst, F. M.; Alt, A. Überprüfung einer Abstinenzbehauptung in der Fahreignungsoberbegutachtung mit Hilfe des Ethanolmetaboliten Ethylglucuronid (EtG). Blutalkohol 1998, 35, 174-182.

32. Sticht, G. GC-MS-Bestimmung von Ethylglucuronid im Serum mit Propylglucuronid als internem Standard. Rechtsmedizin 1997, 7, 184-188. 